\title{
Prevalence and Clinical Relevance of Epstein Barr Virus in Immunocompetent Cases with Pleural Effusion in a Tertiary Health Care
}

\section{Danish Nasar Khan, Shantanu Prakash, Suruchi Shukla, Amita Jain, Shally Awasthi, Surya Kant, Ram Awadh Singh Kushwaha and Rajiv Garg*}

Department of Respiratory Medicine, King George's Medical University, Lucknow, India

*Corresponding Author: Rajiv Garg, Department of Respiratory Medicine, King George's Medical University, Lucknow, India.
Received: June 23, 2021

Published: July 30, 2021

(C) All rights are reserved by Rajiv Garg., et al.

\begin{abstract}
Background: Pleural effusion (PE) is a common pulmonary disorder, affecting over 200000 people per year, worldwide. Primary causes of PE includes cardiac failure, infectious aetiology and malignancy (mostly lung and breast cancer), while the other diseases comprise pulmonary embolism, liver cirrhosis, subphrenic abscess or pancreatitis. Infectious etiology causing PE are bacteria, viruses, tuberculosis, atypical mycobacterium, fungus, as well as parasites. However, exact cause of pleural effusion is generally diagnosed in $\sim 25 \%$ of cases. In India, tuberculosis is the major cause of pleural effusion (PE). PE has been reported in primary EBV infection but the prevalence of EBV is not known. The absence of data from our part of the world has led to this study in all the patients of PE coming to the tertiary care hospital.
\end{abstract}

Methodology: A prospective observational study conducted from January 2014 to Aug 2016 at the Departments of Respiratory Medicine and Microbiology, KGMU, Lucknow. All consecutive suspected patients of PE willing to participate after their informed consent were included. No exclusion criteria were defined. Detailed history, clinical examination, history of medication recorded on pre designed questionnaire. All patients were subjected to routine blood investigations including HIV screening, radiological evaluation and thoracocentesis along with other investigations if needed. Detailed pleural fluid analysis was done as per routine protocol. Mycobacterium tuberculosis was tested in all patients. Additionally, EBV DNA detection and viral load estimation was done by performing Quantitative Real Time PCR in pleural fluid. EBV positive and EBV negative groups were compared for clinical manifestation and biochemical parameters. Data were analyzed using GraphPad Prism software version 5.

Results: Of 439 pleural effusion cases, 277 males and 162 females with mean age of $47.13 \pm 17.81$ and range of 14 - 82 years. After routine screening and testing for aetiology of PE in enrolled cases, TB was detected in 159 (36.22\%) cases, malignancy in 104 (23.69\%), cardiac failure in 30 (6.8\%), urological disease in 9 (2.05\%), $03(0.68 \%)$ from hepatic disease and unknown/unexplained etiology in 134 (30.52\%). Overall, EBV-DNA was detected in 84 (19.13\%) patients. None of the patient was HIV positive. Out of 84 cases, 34 (40.5.\%) patients had high viral load (EBV-DNA VL > 106). EBV positive patients clinically manifested as fever (66\%), thoracic pain (48\%), cough (26\%), lymphadenopathy (21\%), h/o use of oral corticosteriod (18.42\%) and h/o smoking (15.78\%) and alcohol (5.26\%). EBV positive cases were clinically associated with Chronic obstructive pulmonary disorder (COPD) (44\%) and on comparison with EBV negative group, the association was statistically significant. Unfortunately, 11.9.\% mortality (10 patients of 84) was observed in EBV positive patients with high viral load, whereas no mortality was observed from EBV negative group.

Conclusion: Immunocompetent patients with pleural effusion can also be explored for the EBV viral infections especially in associated clinical conditions of COPD. It can also help in predicting the early mortality as there is no treatment exist for its treatment.

Keywords: Epstein Barr Virus; Pleural Effusion; Real Time PCR; Unexplained Aetiology; Pulmonary Infection 


\section{Introduction}

Pleural effusion (PE) is a common pulmonary disorder, affecting over 200000 people per year, worldwide [1]. PE is a common clinical condition that requires a differential diagnosis as it may represent the primary manifestation of certain diseases; however, it is commonly observed as a secondary manifestation or complication of other diseases. Primary causes include cardiac failure, infectious aetiology and malignancy (mostly lung and breast cancer), while the other diseases comprise pulmonary embolism, liver cirrhosis, subphrenic abscess or pancreatitis [1-3]. Infectious etiology causing PE are bacteria, viruses, tuberculosis, atypical mycobacterium, fungus, as well as parasites. Despite of the high prevalence of pleural disease and advancements of research, the aetiology of pleural effusion often remains incomplete [2]; as many cases go away with idiopathic diagnosis or unexplained pleural effusion. However, exact cause of pleural effusion is generally diagnosed in $\sim 25 \%$ of cases only. Unexplained/idiopathic pleural effusion is defined as any $P E$ that fails to achieve a definitive diagnosis after intensive workup i.e. clinical, laboratory and radiological evaluation. Etiological diagnosis mainly depends on pleural fluid analysis and radiological findings [5].

In Indian scenario, tuberculosis (TB) is still the major cause of $\mathrm{PE}$ and cannot be ruled out in unexplained PE cases also. Malignancy takes equal or next major share as etiology of PE. Apart from $\mathrm{TB}$, other infectious etiology of PE still needs to be explored. In this view, we planned our study to look into the role of Epstein-Barr virus (EBV); an important viral etiology affecting patients with pleural effusions. Epstein-Barr virus (EBV), also known as human herpesvirus 4, is a member of the herpes virus family. It is one of the most common human viruses. EBV is found all over the world. Most people get infected with EBV at some point in their lives. EBV spreads most commonly through bodily fluids, primarily saliva. EBV can cause infectious mononucleosis, also called mono, and other illnesses. Antibodies to EBV have been demonstrated in all population groups, with worldwide distribution; approximately 90 to 95 percent of adults are eventually EBV-seropositive. EBV is capable of establishing a lifelong latent infection with intermittent reactivation to lytic replication. In most of the studies done in immunocompromised hosts, Epstein-Barr virus (EBV) has been found to be associated as a causative agent where no other cause was found. Paucity of data of EBV infection in pleural effusion cases in immunocompetent host prompted this study. PE has been reported in primary EBV infection but the prevalence of EBV is not known. Most of the studies related with EBV infection and its association with pathogenesis of PE has been done in western part of the world and data is sparse, moreover it has been done in selected population. The absence of data from our part of the world has led to this study in all the patients of PE coming to the tertiary care hospital. This study was conducted to know the role of EBV infection in pleural effusion patients and their clinical and biochemical profile.

\section{Materials and Methods}

\section{Study design}

A prospective study was conducted from January 2011 to Aug 204 on all consecutive patients of PE (Clinically and radiological confirmed cases) after their informed consent at the Departments of Respiratory Medicine and Microbiology, King George's Medical University (KGMU) Lucknow. Detailed history, clinical examination, history of medication recorded on pre designed questionnaire.

\section{Inclusion criteria}

All the adult patients with the new-onset radiographic or sonographic evidence of pleural effusion and Patients with clinical evidence of pleural effusion. In these patients, the clinical suspicion was confirmed by radiography or sonography.

\section{Exclusion criteria}

Patients with below 14 years of age and Patients already diagnosed with pleural effusion and patients on the treatment for pleural effusion and Patient who already had undergone pleurocentesis.

All the laboratory work was carried out at the virology laboratory of the department of microbiology, Department of Microbiology, KGMU, Lucknow. Ethical clearance was taken from institutional ethics committee.

\section{Sample collection and analysis}

All patients were subjected to radiological evaluation and Pleural fluid aspiration was done. Pleural fluid collected from patients were immediately analysed for cell cytology, protein concentration, glucose estimation and Lactate dehydrogenase (LDH) level. Pleural fluid was further subjected to quantitative real time PCR for EBVDNA assay. EBV positive and EBV negative groups were compared for clinical manifestation and biochemical parameters.

Blood samples were also collected from all the admitted patients for biochemical analysis. On the basis of clinical, biochemical and cytological parameters all PE patients were evaluated for HIV, tuberculosis, malignancy, cardiac, renal or hepatic causes of pleural effusion. 


\section{Molecular assay for EBV DNA detection}

Pleural fluid of all the enrolled patients were analysed for EBV DNA. Total nucleic acid was extracted from $200 \mu \mathrm{l}$ pleural fluid samples using the PureLink Viral RNA/DNA extraction Kit (Invitrogen, Life technologies, CA, USA) following the manufacturer's protocol. Briefly, pleural fluid was centrifuged at $600 \times \mathrm{g}$ for $10 \mathrm{~min}$ at $4^{\circ} \mathrm{C}$; EBV nucleic acid was isolated from the supernatant. Isolated total nucleic acid from pleural effusion was quantified using real-time EBV Taqman PCR. Each real time PCR consisted of positive, negative and extraction controls. The result were reported only if all the controls were valid. EBV DNA was detected by using the primer and Probes of non-glycosylated membrane antigen BNRFp143 gene of EBV as mentioned by Niesters HG., et al. 2010 [11]. Real time RTPCR assays were performed on Quantstudio 7 (Life Technologies, USA). The pleural fluid was subjected to real time PCR for detecting the presence of EBV DNA and its viral load was quantified using positive controlled cloned standards.

\section{Statistical analysis}

Results are presented as mean \pm SD of three independent experiments and differences between two groups were analyzed for statistical significance by student's t test using GraphPad Prism 5 software (San Diego, CA). Differences with $p<0.05$ were considered statistically significant.

\section{Results}

Total 439 patients were enrolled in the study. 277 males and 162 females with mean age of $47.13 \pm 17.81$ and range of $14-82$ years (Table 2). Majority of these cases were in 30 - 59 years range. After routine screening and testing for aetiology of PE in enrolled cases, TB was detected in 159 (36.21\%) cases, malignancy in 104 (23.69\%), cardiac failure in 30 (6.8\%), urological disease in 09 (2.05\%), $03(0.68 \%)$ from hepatic disease and unknown/unexplained etiology in 134 (30.52\%) (Table 1 and figure 1). None of the patient was HIV positive.

\begin{tabular}{|c|c|c|c|c|c|c|c|}
\hline Parameters & $\begin{array}{c}\text { EBV } \\
\text { Positive }\end{array}$ & Percentage & $\begin{array}{c}\text { EBV } \\
\text { Negative }\end{array}$ & Percentage & P - Value & $\begin{array}{c}\text { Total PE } \\
\text { Cases }\end{array}$ & $\begin{array}{c}\text { Distribution of } \\
\text { PE cases (\%) }\end{array}$ \\
\hline Tuberculosis & 35 & 41.67 & 124 & 34.93 & 0.577 & 159 & 36.22 \\
\hline Malignancy & 15 & 17.86 & 89 & 25.07 & 0.677 & 97 & 22.10 \\
\hline Cardiovascular disorder & 9 & 10.71 & 21 & 5.92 & 0.731 & 24 & 5.47 \\
\hline Renal Failure & 0 & 0.00 & 9 & 2.54 & - & 9 & 2.05 \\
\hline Liver cirrhosis & 0 & 0.00 & 3 & 0.85 & - & 3 & 0.68 \\
\hline Unknown etiology & 25 & 29.76 & 109 & 30.07 & 0.552 & 147 & 33.49 \\
\hline Total & 84 & 100 & 355 & 100 & - & 439 & 100.00 \\
\hline
\end{tabular}

Table 1: Aetiology of PE in enrolled cases.

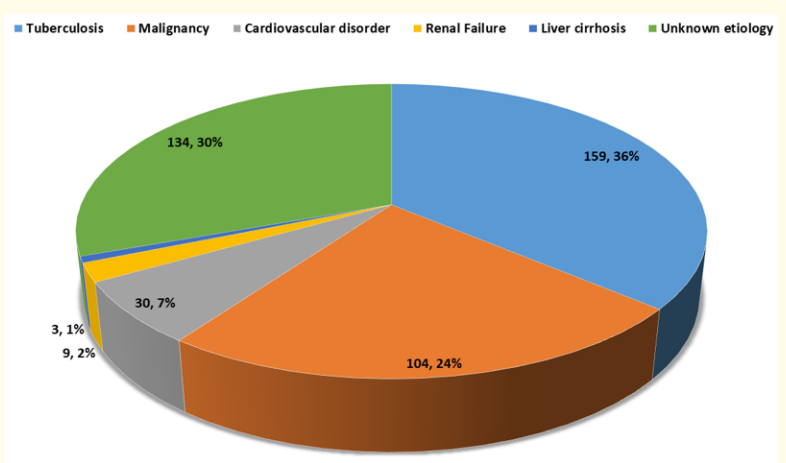

Figure 1: Total no. of cases and percent distribution.

*TB was demonstration of high ADA levels/demonstration of acidfast bacilli (AFB)/The Liquid culture/LPA.

\#The malignancy was diagnosed based on the demonstration of malignant cells in the pleural fluid or on the histopathological examination of pleural biopsy specimens.
Overall, EBV-DNA was detected in 84 (19.13\%) patients. Percentage positivity (Figure 2) of EBV is similar in TB, Malignancy and patients of unknown etiology. EBV infection was not found in Renal and hepatic pleural effusion cases.

Out of 84 cases, 34 patients had high viral load (EBV-DNA VL $>10^{6}$ ). Both the EBV positive group and EBV negative group was compared. It was observed there were more male (63\%) patients than female (37\%) in EBV positive group and association was statistically significant. EBV positive patients clinically manifested as fever (66\%), thoracic pain (48\%), cough (26\%), lymphadenopathy (21\%), h/o use of oral corticosteroid (18.42\%) and h/o smoking (15.78\%) and alcohol (5.26\%). However, none of the patients in this group had kidney or liver cirrhosis pathology. EBV positive cases were clinically associated with Chronic obstructive pulmonary disorder (COPD) (44\%) and on comparison with EBV negative group, the association was statistically significant (Table 3). 


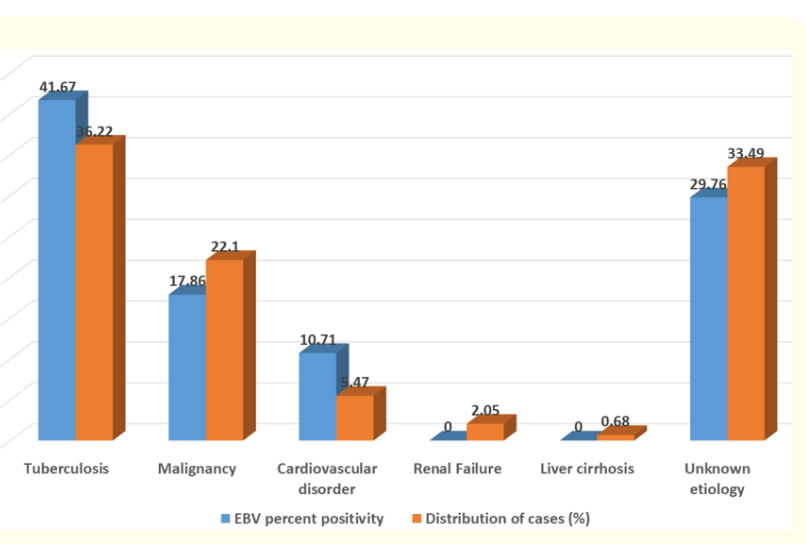

Figure 2: Distribution of cases and percent positivity of EBV in different diagnosis.

During radiological examination of chest it was observed in EBV positive group majority of patient had right chest (68\%) pleurisy and very few patients had bilateral (13\%) effusion in the EBV positive patients. Whereas, EBV negative patients had bilateral (40\%) pleurisy. Pleural fluid collected from EBV positive patients had high glucose level $(100.6 \pm 61.4 \mathrm{mg} / \mathrm{dL})$ as compared to EBV negative patients $(69.1 \pm 23.3 \mathrm{mg} / \mathrm{dL})$ (Table 4$)$, however it was statistically insignificant. The protein concentration and LDH level was found higher in pleural fluid in EBV positive patients compared to EBV negative group and was statistically significant. Out of 84 EBV positive patients 63 patients had exudative pleural effusion and 21 patients had transudative pleural effusion. Most of the EBV positive patients were having exudative pleural effusion and pleural effusion from EBV negative patients was mostly transudative in nature as expected in viral pleural effusion [3].

Unfortunately, $11.9 \%$ mortality (10 patients of 84 ) was observed in EBV positive patients with high viral load, whereas no mortality was observed from EBV negative group.

\section{Discussion}

EBV infects $>90 \%$ of the population worldwide and, like other herpes viruses, it is able to establish a lifelong latent infection with intermittent reactivation to lytic replication. EBV is mostly transmitted through saliva, and primary infection usually occurs subclinically in infancy and childhood [5]. In our study we studied the prevalence $(19.13 \%)$ of most ubiquitous EBV in the patients of pleural effusion. A possible role of EBV in causing pleural effusion has been described in Netherlands by Thijsen., et al. [2]. The author observed high prevalence (19.13\%) of EBV positivity in pleural fluid by real time PCR. However, none of the Indian study reported prevalence of EBV in pleural effusion patients [2]. To the best of my knowledge this is the first study exploring the EBV infection from our part of the world and is also probably the first study done in immunocompetent patients. The prevalence of 19\% EBV infection in $\mathrm{PE}$ is not that uncommon as compared to immunocompromised hosts.

Thijsen., et al. even reported mortality in high EBV viral load > 10,000geq-meq/ml within 6 months; Whereas we observed mortality in ten patient in EBV positive group with viral load $>10,000$ geq-meq/ml; high viral load leading to mortality could be due to active replication of EBV virus, which remains latent otherwise. Therefore, we should select real time polymerase chain reaction for diagnosis as well as quantitative estimation of EBV viral load in pleural effusion.

Among the known causes of pleural effusion we found that Mycobacterial infection and malignancies are the major causes and were also associated with EBV as shown in figure 2. Our data was in concordance with the report of author Shang-Gin Wu., et al. 2013, [19] who has shown strong correlation between pleural effusion in malignant patients. Similarly, according to Porcel JM [6] has also shown prevalent in tubercular pleural effusions. Apart from them we also found renal, hepatic and cardiac collapse causing pleural effusion but it was not associated with EBV infection. $29.76 \%$ of population in EBV positive group was previously classified in unexplained aetiology. Our data is in accord with the previous study reported which showed $20 \%$ association of EBV in causing pleural effusion [17]. As reported by Thijsen., et al. [2] we also find male patients with age 50 years are more prone to active EBV infection. Reason behind this selection could not be explained.

Since pleural effusion patients with unknown aetiology suffer from the drawback of incomplete treatment it is very important to diagnose such cases for better management of disease. The current study was able to establish apparent association of EBV in developing pleural effusion. EBV infection in pleural effusion patients followed its typical manifestation in any other diseases.

There were no significant differences in EBV positive PE patients compared to negative except that it was more common in 
patients having COPD as co morbidity shown in table 2-4. The EBV positivity was similar in undiagnosed as compared to known etiological conditions of PE. The increased viral load was associated with early mortality which needs to be explored further.

\begin{tabular}{|c|c|c|c|}
\hline $\begin{array}{c}\text { Clinical } \\
\text { Parameter }\end{array}$ & $\begin{array}{c}\text { EBV Positive } \\
\text { (RT-PCR) } \\
\text { N- 84 (\%) }\end{array}$ & $\begin{array}{c}\text { EBV Negative } \\
\text { (RT-PCR) } \\
\text { N-355 (\%) }\end{array}$ & $\begin{array}{c}\mathbf{p} \text { - Value } \\
\text { Student 't' } \\
\text { test }\end{array}$ \\
\hline $\begin{array}{c}\text { Number of } \\
\text { cases }\end{array}$ & $\begin{array}{c}84(19)(34 \text { with } \\
\left.\text { VL }>10^{6}\right)\end{array}$ & $355(81)$ & $<0.05$ \\
\hline $\begin{array}{c}\text { Average Age } \\
\text { (years) }\end{array}$ & $49.6 \pm 17.9$ & $51.2 \pm 16.8$ & $<0.05$ \\
\hline Male & $53(63)$ & $195(54.9)$ & $<0.05$ \\
\hline Female & $31(37)$ & $160(45.1)$ & $<0.05$ \\
\hline
\end{tabular}

Table 2: Association of age and gender among EBV positives and negatives.

\begin{tabular}{|c|c|c|c|}
\hline $\begin{array}{c}\text { Clinical } \\
\text { Parameter }\end{array}$ & $\begin{array}{c}\text { EBV Positive } \\
\text { (RT-PCR) } \\
\text { N- 84(\%) }\end{array}$ & $\begin{array}{c}\text { EBV Negative } \\
\text { (RT-PCR) } \\
\text { N-355 (\%) }\end{array}$ & $\begin{array}{c}\boldsymbol{p} \text { - Value } \\
\text { Student 't' } \\
\text { test }\end{array}$ \\
\hline Fever & $55(65.48)$ & $146(41)$ & $<0.05$ \\
\hline Thoracic pain & $40(47.6 \%)$ & $241(68 \%)$ & $<0.05$ \\
\hline Cough & $22(26 \%)$ & $92(26 \%)$ & 1.0 \\
\hline $\begin{array}{c}\text { Tuberculosis } \\
\text { confirmed }\end{array}$ & $\begin{array}{c}35(41.67) \mathrm{VL} \\
>10^{6}\end{array}$ & $124(34.93)$ & $<0.05$ \\
\hline $\begin{array}{c}\text { Malignancy } \\
\text { confirmed }\end{array}$ & $\begin{array}{c}15(17.86) \mathrm{VL} \\
\left(\mathrm{VL}>10^{6} \text { in } 1\right)\end{array}$ & $89(25.07)$ & $<0.05$ \\
\hline $\begin{array}{c}\text { Cardiovascu- } \\
\text { lar disorder }\end{array}$ & $9(10.71) \mathrm{VL}$ & $21(5.92)$ & $<0.05$ \\
\hline Renal Failure & $0(0)$ & $9(2.54)$ & $<0.05$ \\
\hline $\begin{array}{c}\text { Liver cir- } \\
\text { rhosis }\end{array}$ & $0(0)$ & $3(0.85)$ & $<0.05$ \\
\hline $\begin{array}{c}\text { Unknown } \\
\text { Etiology }\end{array}$ & $25(29.76)$ & $109(30.07)$ & 0.89 \\
\hline $\begin{array}{c}\text { Mortality } \\
\text { had malignancy) }\end{array}$ & $\begin{array}{c}11(11.9) \text { with } \\
\text { VL } 10^{6}(0 n e\end{array}$ & $0(0)$ & $<0.05$ \\
\hline
\end{tabular}

Table 3: Association of different symptoms and comorbidities among EBV positives and negatives.

\begin{tabular}{|c|c|c|c|}
\hline $\begin{array}{c}\text { Clinical } \\
\text { Parameter }\end{array}$ & $\begin{array}{l}\text { EBV Positive } \\
\text { (RT-PCR) } \\
\text { N- 84(\%) }\end{array}$ & $\begin{array}{c}\text { EBV Negative } \\
\text { (RT-PCR) } \\
\text { N-355 (\%) }\end{array}$ & $\begin{array}{c}p \text { - Value } \\
\text { Student } \\
\text { 't' test }\end{array}$ \\
\hline \multicolumn{4}{|c|}{ Pleural fluid and serum evaluation } \\
\hline $\begin{array}{l}\text { Glucose }(\mathrm{mg} / \mathrm{dL}) \\
\text { (Normal range } 48 \\
\text { to } 148 \mathrm{mg} \% \text { ) }\end{array}$ & $74.4 \pm 27.9$ & $100.6 \pm 61.4$ & $<0.05$ \\
\hline $\begin{array}{c}\text { PF LDH (IU/L) } \\
\text { (Normal range } \\
124 \mathrm{U} / \mathrm{L}\end{array}$ & $549.5 \pm 122.4$ & $435 \pm 117.5$ & $<0.05$ \\
\hline $\begin{array}{c}\text { PF protein }(\mathrm{g} / \mathrm{dL}) \\
1-2 \mathrm{~g} / \mathrm{L}\end{array}$ & $4.1 \pm 0.6$ & $2.1 \pm 0.8$ & $<0.05$ \\
\hline $\begin{array}{l}\text { Transudate (using } \\
\text { Light's criteria) }\end{array}$ & $21(24)$ & $259(73)$ & $<0.05$ \\
\hline $\begin{array}{l}\text { Exudate (using } \\
\text { Light's criteria) } \\
\text { Lymphocyte/ } \\
\text { Polymorph }\end{array}$ & $63(76)$ & $96(27)$ & $<0.05$ \\
\hline $\begin{array}{c}\text { TLC cells/cu.m } \\
0-500 \\
>500-1000 \\
>1000\end{array}$ & $\begin{array}{l}35 \\
09 \\
40\end{array}$ & $\begin{array}{c}194 \\
144 \\
17\end{array}$ & $\begin{array}{l}<0.05 \\
<0.05\end{array}$ \\
\hline $\begin{array}{c}\text { Differential cell } \\
\text { count } \\
\text { Polymorphs } \\
\text { Lymphocytes } \\
\text { Other cells }\end{array}$ & $\begin{array}{c}25.60 \pm 24.77 \\
72.15 \pm 24.80 \\
1.89 \pm 4.54\end{array}$ & $\begin{array}{c}25.49 \pm 25.35 \\
72.36 \pm 25.83 \\
1.08 \pm 2.76\end{array}$ & $\begin{array}{l}0.97 \\
0.94 \\
0.03\end{array}$ \\
\hline $\begin{array}{l}\text { PF location } \\
\text { Left n (\%) } \\
\text { Right n (\%) } \\
\text { Bilateral n (\%) }\end{array}$ & $\begin{array}{l}15(18) \\
58(69) \\
11(13)\end{array}$ & $\begin{array}{l}99(28) \\
114(32) \\
142(40)\end{array}$ & $\begin{array}{l}<0.05 \\
<0.05 \\
<0.05\end{array}$ \\
\hline
\end{tabular}

Table 4: Association of different clinical parameters among EBV positives and negatives.

\section{Limitation of the Study}

Limitation of this study was that it does not differentiate active EBV infection from latent and lytic infection.

\section{Conclusion}

Immunocompetent patients can also be explored for the EBV viral infections especially in associated clinical conditions of COPD 
and can also help in predicting the early mortality as there is no treatment exist for its treatment. Further studies are needed to prove these findings especially in immunocompetent patients.

\section{Conflict of Interest}

None to declare.

\section{Funding/Grants}

Indian Council of Medical Research, New Delhi for financial support [5/8/7/17/2010-ECD-1].

Institutional ethical clearance: VIR/29/2011-ECD-1.

\section{Acknowledgement}

Staff of Viral Diagnostics Laboratory, Department of Microbiology for support in lab work.

\section{Bibliography}

1. Sriram PS and Antony VB. "Advances in pleural disease". Drug Discovery Today: Disease Mechanisms 4 (2007): 103-108.

2. Thijsen SFT., et al. "A possible role for Epstein-Barr virus in the pathogenesis of pleural effusion". European Respiratory Journal 26 (2005): 662-666.

3. Mohan KM and Ravindran C. "Etiology and clinical profile of pleural effusion in a teaching hospital of South India: A descriptive study". Pulmon 14 (2012): 89-96.

4. Raghavan S., et al. "Clinical and etiological profile of patients with pleural effusion in a tertiary care centre". Journal of Medical Science and Clinical Research 5 (2017): 23553-23558.

5. Amber Degryse and Richard W Light. "Antimicrobe-Infectious disease and antimicrobial agents". Authorative Database.

6. Porcel M and Light RW. "Disease-a-Month Pleural effusions". Disease-a-Month 59 (2013): 29-57.

7. Martro E and Ausina V. "The role of Epstein-Barr virus in pleural effusions of unknown aetiology: an interesting clinical perspective”. European Respiratory Journal 26 (2005): 566-568.

8. Porcel JM., et al. "The diagnosis of pleural effusions". Expert Review of Respiratory Medicine (2015): 1-15.
9. Middeldorp JM., et al. "Pathogenic roles for Epstein-Barr virus (EBV) gene products in EBV-associated proliferative disorders". Critical Reviews in Oncology/Hematology 45 (2003): $1-36$.

10. Grywalska E., et al. "Epstein-Barr virus-associated lymphomas". Seminar on Oncology 42 (2015): 291-303.

11. Hatton OL., et al. "The interplay between Epstein-Barr virus and B lymphocytes: Implications for infection, immunity, and disease". Immunology Research 58 (2014): 268-276.

12. Heffner E and Brown LK. "Diagnostic Value of Tests That Discriminate Between Exudative and Transudative Pleural Effusions". Chest 111 (1997): 970-980.

13. Niesters HG., et al. "Development of a real-time quantitative assay for detection of Epstein-Barr virus". Journal of Clinical Microbiology 38 (2000): 712-715.

14. Middeldorp JM., et al. "Pathogenic roles for Epstein-Barr virus (EBV) gene products in EBV-associated proliferative disorders". Critical Reviews in Oncology/Hematology 45 (2003): 1-36.

15. Kimura H., et al. "Quantitative Analysis of Epstein-Barr Virus Load by Using a Real-Time PCR Assay". Journal of Clinical Microbiology 37 (1999): 132-136.

16. Venkitaraman AR., et al. "The seroepidemiology of infection due to Epstein-Barr virus in southern Indian Journal of Medical Virology 15 (1985): 11-16.

17. Dinand V., et al. "Hodgkin's lymphoma in Indian children: Prevalence and significance of Epstein-Barr virus detection in Hodgkin's and Reed-Sternberg cells". European Journal of Cancer 43 (2007): 161-168.

18. Rymbai ML., et al. "Frequency of Epstein--Barr virus infection as detected by messenger RNA for EBNA 1 in histologically proven gastric adenocarcinoma in patients presenting to a tertiary care center in South India". Indian Journal of Medical Microbiology 33 (2015): 369-373.

19. Vinaya S Karkhanis and Jyotsna M Joshi. "Pleural effusion: diagnosis, treatment, and management". Open Access Emergency Medicine 4 (2012): 31-52. 
20. Takei H and Mody D. "Epstein-Barr virus positive pleural effusion: clinical features, cytomorphologic characteristics, and flow cytometric immunophenotyping". American Journal of Clinical Pathology 142 (2014): 788-794.

21. Wu SG., et al. "Survival of lung adenocarcinoma patients with malignant pleural effusion". European Respiratory Journal 41 (2013): 1409-1418.

\section{Volume 5 Issue 8 August 2021}

(C) All rights are reserved by Rajiv Garg., et al. 